\title{
Is there any difference between the iodine statuses of breast-fed and formula- fed infants and their mothers in an area with iodine sufficiency?
}

\author{
Pantea Nazeri ${ }^{1,2}$, Hosein Dalili ${ }^{1}$, Yadollah Mehrabi ${ }^{3}$, Mehdi Hedayati $^{4}$, Parvin Mirmiran ${ }^{2 *}$ and Fereidoun Azizi ${ }^{5 *}$ \\ ${ }^{1}$ Breastfeeding Research Center, Family Health Institute, Tebran University of Medical Sciences, Tehran 1419943471, Iran \\ ${ }^{2}$ Nutrition and Endocrine Research Center, Research Institute for Endocrine Sciences, Shabid Beheshti University of Medical \\ Sciences, Tehran 1985717413, Iran \\ ${ }^{3}$ Department of Epidemiology, School of Public Health, Shabid Beheshti University of Medical Sciences, Tehran 1983535511, Iran \\ ${ }^{4}$ Cellular and Molecular Research Center, Research Institute for Endocrine Sciences, Shahid Beheshti University of Medical \\ Sciences, Tehran 1985717413, Iran \\ ${ }^{5}$ Endocrine Research Center, Research Institute for Endocrine Sciences, Shabid Beheshti University of Medical Sciences, Tehran \\ 1985717413 , Iran
}

(Submitted 19 August 2017 - Final revision received 20 December 2017 - Accepted 23 January 2018 - First published online 5 March 2018)

\section{Abstract}

Despite substantial progress in the global elimination of iodine deficiency, lactating mothers and their infants remain susceptible to insufficient iodine intake. This cross-sectional study was conducted to compare iodine statuses of breast-fed and formula-fed infants and their mothers at four randomly selected health care centres in Tehran. Healthy infants $<3$ months old and their mothers were randomly selected for inclusion in this study. Iodine was measured in urine and breast milk samples from each infant and mother as well as commercially available infant formula. The study included 124 postpartum mothers (29.2 (SD 4.9) years old) and their infants (2.0 (sD 0.23) months old). The iodine concentrations were $50-184 \mu \mathrm{g} / \mathrm{l}$ for infant formula, compared with a median breast milk iodine concentration (BMIC) of $100 \mu \mathrm{g} / \mathrm{l}$ in the exclusive breast-feeding group and $122 \mu \mathrm{g} / \mathrm{l}$ in the partial formula feeding group. The median values for urinary iodine concentration in the exclusive breast-feeding group were $183 \mu \mathrm{g} / \mathrm{l}$ (interquartile range (IQR) 76-285) for infants and $78 \mu \mathrm{g} / \mathrm{l}$ (IQR 42-145) for mothers, compared with $140 \mu \mathrm{g} / \mathrm{l}$ (IQR 68-290) for infants and $87 \mu \mathrm{g} / \mathrm{l}$ (IQR 44-159) for mothers in the formula feeding group. These differences were not statistically significant. After adjustment for BMIC, ANCOVA revealed that feeding type (exclusive breast-feeding $v$. partial formula feeding) did not significantly affect the infants' or mother's urinary iodine levels. Thus, in an area with iodine sufficiency, there was no difference in the iodine statuses of infants and mothers according to their feeding type.

Key words: Urinary iodine concentration: Breast-fed infants: Formula-fed infants: Breast milk iodine concentrations: Infant formula: Iran

Iodine deficiency (ID) is an important micronutrient deficiency, given iodine's critical role in fetal neurologic development ${ }^{(1-4)}$. The severe form of ID can cause cretinism, congenital anomalies, intellectual impairment, growth retardation and infant mortality $^{(5-7)}$, whereas, even mild ID can impair children's neurointellectual development ${ }^{(8-10)}$. Although, there has been substantial progress in the global elimination of ID, lactating mothers and their infants remain susceptible to insufficient iodine intake ${ }^{(11)}$.

Iodine sufficiency among lactating mothers is particularly important for exclusively breast-fed infants, as breast milk is their only source of iodine during a critical period of growth and development ${ }^{(12)}$. Based on biological mechanisms, it is plausible that urinary iodine concentrations (UIC), which reflect iodine status, are positively associated among mothers and their exclusively breast-fed infants ${ }^{(12)}$. Interestingly, results from Turkey $^{(13)}$, Ireland ${ }^{(14)}$, China ${ }^{(15)}$ and Iran ${ }^{(16,17)}$ indicate that, the transfer of iodine from mother to infant results is the infant having higher UIC values, it was also accompanied by an increase in the proportion of lactating mothers with inadequate UIC values. Moreover, a few studies that specifically assessed iodine status among formula feeding mothers revealed conflicting findings. For example, one study found no difference in the median UIC values of mothers who were breast-feeding or formula feeding ${ }^{(18)}$. However, another study revealed significantly increased UIC values among breast-feeding mothers, compared with formula feeding mothers ${ }^{(14)}$.

Neonates and infants receive their entire supply of iodine from breast milk and/or formula. Thus, Europe requires infant

\footnotetext{
Abbreviations: BMIC, breast milk iodine concentration; ID, iodine deficiency; IQR, interquartile range; UIC, urinary iodine concentration.
} 
formula to contain $10-50 \mu \mathrm{g}$ of iodine $/ 418 \cdot 4 \mathrm{~kJ}$ (100 kcal), whereas the USA requires approximately $5-75 \mu \mathrm{g} / 100 \mathrm{kcal}$. However, despite the importance of iodine during these critical periods, few studies have compared the iodine statuses of breastfed and formula-fed infants. In addition, studies from areas with iodine sufficiency have revealed inconclusive results. For instance, in the USA, no significant differences in UIC values were detected among infants who were exclusively breast-fed, formula-fed or receiving a combination of breast milk and formula $^{(19)}$. In contrast, the median UIC was significantly lower among Chinese infants who were exclusively formula-fed, compared with those who were exclusively breast-fed ${ }^{(15)}$. Another study in Switzerland, which is a country with iodine sufficiency, indicated that infants who were exclusively or partially formula-fed had a better iodine status, compared with exclusively breast-fed infants ${ }^{(20)}$.

Therefore, based on the limited data and the conflicting results regarding the effect of feeding type on infants' iodine status in areas with iodine sufficiency, the present study compared the UIC values from breast-fed and formula-fed infants and their mothers in an area that has had iodine sufficiency for more than two decades.

\section{Methods}

\section{Subjects}

This cross-sectional study was conducted between December 2014 and March 2015 at four randomly selected health care centres in Tehran. Among 140 healthy mothers and their infants who were referred for routine check-ups, the present study included 124 infants who were $<3$ months old and either exclusively breast-fed or exclusively/partially formula-fed, as well as their mothers. The infants and mothers were enrolled with unequal sample sizes from each health care centre. Mothers and infants with a history of thyroid disorders and those who were currently using iodine-containing supplements and disinfectants were excluded. An interviewer-administered questionnaire was used to collect data regarding maternal age, education, occupation, date of last pregnancy, gravidity, parity, history of abortion and use of iodine-containing supplements during pregnancy. In addition, data were collected regarding the infants' birth date, sex, birth weight, height and head measurements, type of feeding and brand of infant formula (where applicable). Written informed consent was obtained from the parents after they received an explanation of the study's protocol and objectives. The study's protocol was approved by the ethics committee of the Research Institute for Endocrine Sciences (RIES), Shahid Beheshti University of Medical Sciences.

\section{Urine and breast milk sample collection}

At the first visit, labelled plastic bottles and adhesive paediatric urine bags (SUPA Medical Services) were provided to collect spot urine samples from each mother and infant, according to the manufacturer's detailed instructions. Mothers were asked to collect a casual infant urine sample at a random point during the day, after cleaning the infant's genital region. For boys, the entire penis was placed in the bag and the adhesive was pressed against their skin. For girls, the bag was positioned to cover the labia. If the infant's urine sample could not be collected after three attempts, the mothers were asked to obtain a sample by holding a specimen bottle in the urine stream. Lactating mothers who were exclusively or partially breastfeeding were asked to manually express their breast milk at the time of urine collection. All samples of urine and breast milk were collected and stored at room temperature, before being sent to the RIES laboratory, where they were transferred into screw-top labelled plastic vials. The aliquots were subsequently frozen at $-20^{\circ} \mathrm{C}$ until the iodine concentrations were measured.

\section{Salt sample collection}

Two tablespoon-sized samples of cooking and/or table salt were obtained from each mother at the time of urine collection. Some mothers used two types of salt, and samples of both were collected in those cases. The samples were stored in lightproof, closed plastic containers that were labelled with the mother's identification code.

\section{Infant formula selection}

Information on different types of formula for infants from birth to 6 months of age was obtained from the Food and Drug Administration, Ministry of Health and Medical Education. Based on the list of formula brands currently available in the Tehran markets, the bands most frequently used were selected. From each brand, three samples were purchased from referral pharmacies and sent to the RIES laboratory for iodine testing.

\section{Laboratory measurements}

Iodine concentrations in the urine, breast milk and infant formula samples were analysed using the Sandell-Kolthoff (aciddigestion) reaction ${ }^{(21)}$. The results were expressed as $\mu \mathrm{g}$ of iodine per litre of urine and milk, or as $\mu \mathrm{g} / 100 \mathrm{ml}$ of infant formula. Breast milk and formula samples were carefully homogenised before the alkaline ashing procedure. Intra-assay CV for UIC were $8 \%$ at $8 \mu \mathrm{g} / 1,6 \%$ at $17 \mu \mathrm{g} / 1$ and $8 \%$ at $36 \mu \mathrm{g} / \mathrm{l}$. The inter-assay CV for UIC were $10 \%$ at $8 \mu \mathrm{g} / 1,10 \%$ at $17 \mu \mathrm{g} / 1$ and $8 \%$ at $36 \mu \mathrm{g} / \mathrm{l}$. The intra-assay $\mathrm{CV}$ for breast milk iodine concentration (BMIC) were $9 \%$ at $3 \mu \mathrm{g} / 1,7 \%$ at $13 \mu \mathrm{g} / 1$ and $9 \%$ at $36 \mu \mathrm{g} / \mathrm{l}$. The inter-assay CV for BMIC were $10 \%$ at $3 \mu \mathrm{g} / \mathrm{l}, 9 \%$ at $13 \mu \mathrm{g} / \mathrm{l}$ and $12 \%$ at $36 \mu \mathrm{g} / \mathrm{l}$. The intra-assay and inter-assay CV for the infant formula samples were both $9 \%$. The salt samples' iodine concentrations in parts per million (ppm) were determined using the iodometric titration method, which has a sensitivity of $1 \mathrm{ppm}$ and a $\mathrm{CV}$ of $1 \%$.

\section{Definitions}

Exclusive breast-feeding was defined according to the WHO's criteria as no non-breast milk food or drink, including water, being used for nourishment. Exclusive formula feeding was defined as the infant only being fed using a standard commercially available cow's milk-based formula. Partial breast and formula feeding was defined as the infant receiving both breast milk and formula. According to international criteria, median 
UIC values $<100 \mu \mathrm{g} / \mathrm{l}$ and $\geq 100 \mu \mathrm{g} / \mathrm{l}$ were defined as indicating ID and adequacy, respectively, among postpartum mothers and their infants ${ }^{(22)}$. A median BMIC of $\geq 100 \mu \mathrm{g} / 1$ is defined as adequate in areas with iodine sufficiency ${ }^{(23)}$.

\section{Statistical analysis}

Data were reported as numbers and percentages, mean values and standard deviations or medians and interquartile ranges (IQR)), as appropriate. Normality of the variables' distributions was assessed using the Kolmogorov-Smirnov test and histogram charts. Inter-group comparisons were performed using the $\chi^{2}$ test, Mann-Whitney test, or $t$ test, as appropriate. Spearman's correlation analysis was used to examine the correlations between the infants' UIC values and potentially related variables. ANCOVA was also used to examine the effect of feeding type (exclusive breast-feeding $v$. partial formula feeding) on the mothers' and infants' iodine statuses. All statistical analyses were performed using IBM SPSS software (version 20.0; IBM Corp.), and differences were considered significant at a $P$ value of $<0 \cdot 05$. Post hoc power analysis was performed using G*Power software (version 3.1.0) and based on the mean difference in the UIC values according to feeding type. Using an effect size of $=0.5$ (based on previously reported data) ${ }^{(17,13,18)}$, an error probability ratio $(\beta: \alpha)$ of $=4$, and the two groups' sample sizes (breast-feeding: seventy-one cases, formula feeding: fifty-three cases), the present study had an estimated statistical power of 0.787 .

\section{Results}

The present study included 124 mothers (29.2 (sD 4.9) years old) and 124 infants (2.0 (SD 0.23) months old). Among the infants, $57 \%$ were exclusively breast-fed and $43 \%$ were formula-fed (exclusively or partially). The mothers' and infants' characteristics are shown in Table 1. No significant differences were observed between the breast-fed and formula-fed groups in terms of infant sex, birth weight, height and head circumference, weight-for-length $z$ score, or length-for-age $z$ score, as well as maternal age, education, date of last pregnancy, gravidity, parity, history of abortion, or use of iodinecontaining supplements during pregnancy. Table 2 shows the UIC and BMIC values for the mothers and infants according to feeding type. The median UIC values were $183 \mu \mathrm{g} / \mathrm{l}$ (IQR 76-285) for breast-fed infants, compared with $140 \mu \mathrm{g} / \mathrm{l}$ (IQR 68-290) for formula-fed infants $(P=0 \cdot 810)$. The median UIC values were $78 \mu \mathrm{g} / 1$ (IQR 42-145) for breast-feeding mothers, compared with $87 \mu \mathrm{g} / \mathrm{l}$ (IQR 44-159) for formula feeding mothers $(P=0.421)$. Among breast-feeding mothers, UIC values of $<100$ and $<50 \mu \mathrm{g} / \mathrm{l}$ were observed in 68 and $33 \%$, respectively,

Table 1. Basic characteristic of infants and their mothers by type of feeding (Numbers and percentages; mean values and standard deviations)

\begin{tabular}{|c|c|c|c|c|c|c|c|c|c|}
\hline \multirow[b]{3}{*}{ Characteristics } & \multicolumn{8}{|c|}{ Type of feeding } & \multirow[b]{3}{*}{$P$} \\
\hline & \multicolumn{4}{|c|}{ Breast-feeding ${ }^{\star}$} & \multicolumn{4}{|c|}{ Formula feeding $†$} & \\
\hline & $n$ & $\%$ & Mean & SD & $n$ & $\%$ & Mean & SD & \\
\hline \multicolumn{10}{|l|}{ Infants } \\
\hline \multicolumn{10}{|l|}{ Sex } \\
\hline Male & 38 & 53.5 & & & 32 & $60 \cdot 4$ & & & 0.446 \\
\hline Female & 33 & 46.5 & & & 21 & $39 \cdot 6$ & & & \\
\hline Birth weight (kg) & & & $3 \cdot 34$ & 0.4 & & & $3 \cdot 21$ & 0.5 & 0.417 \\
\hline Birth height $(\mathrm{cm})$ & & & $50 \cdot 1$ & $2 \cdot 2$ & & & $49 \cdot 6$ & 2.5 & 0.187 \\
\hline Birth head circumference $(\mathrm{cm})$ & & & 34.9 & 1.5 & & & 34.5 & 1.4 & 0.067 \\
\hline Weight-for-length $z$ score & & & -0.25 & $1 \cdot 3$ & & & -0.27 & 1.5 & 0.964 \\
\hline Length-for-age $z$ score & & & 0.29 & $1 \cdot 2$ & & & 0.03 & $1 \cdot 3$ & 0.265 \\
\hline \multicolumn{10}{|l|}{ Mothers } \\
\hline Age (years) & & & 28.9 & $4 \cdot 7$ & & & $29 \cdot 6$ & $5 \cdot 1$ & 0.496 \\
\hline Education (years) & & & $11 \cdot 1$ & 3.7 & & & $11 \cdot 1$ & 3.4 & 0.998 \\
\hline Last date of pregnancy (years) & & & $4 \cdot 0$ & 4.4 & & & $3 \cdot 8$ & 4.5 & 0.770 \\
\hline \multicolumn{10}{|l|}{ Gravidity } \\
\hline Primigravidity & 20 & $28 \cdot 2$ & & & 17 & $32 \cdot 1$ & & & 0.642 \\
\hline Multigravidity & 51 & $71 \cdot 8$ & & & 36 & $67 \cdot 9$ & & & \\
\hline \multicolumn{10}{|l|}{ Parity } \\
\hline Primiparity & 26 & $36 \cdot 6$ & & & 22 & 41.5 & & & 0.502 \\
\hline Multiparity & 14 & 63.4 & & & 31 & $58 \cdot 5$ & & & \\
\hline \multicolumn{10}{|l|}{ History of abortion } \\
\hline Yes & 18 & 25.4 & & & 13 & 24.5 & & & 0.917 \\
\hline No & 53 & $74 \cdot 6$ & & & 40 & $75 \cdot 5$ & & & \\
\hline \multicolumn{10}{|c|}{ Use of iodine-containing supplements during pregnancy } \\
\hline Yes & 5 & $7 \cdot 0$ & & & 6 & $11 \cdot 3$ & & & 0.407 \\
\hline No & 66 & $93 \cdot 0$ & & & 47 & $88 \cdot 7$ & & & \\
\hline \multicolumn{10}{|c|}{ lodine content of salt (parts per million) } \\
\hline$<20$ & 12 & $17 \cdot 9$ & & & 13 & $26 \cdot 0$ & & & 0.451 \\
\hline $20-40$ & 48 & 71.6 & & & 34 & $68 \cdot 0$ & & & \\
\hline$>40$ & 7 & $10 \cdot 4$ & & & 3 & $6 \cdot 0$ & & & \\
\hline
\end{tabular}

* Exclusive breast- feeding.

† Exclusive or partial formula feeding. 
Table 2. Urinary and breast milk iodine concentrations in infants and their mothers by type of feeding (Numbers and percentages; medians and interquartile ranges (IQR))

\begin{tabular}{|c|c|c|c|c|c|}
\hline \multirow[b]{3}{*}{ Variables } & \multicolumn{4}{|c|}{ Type of feeding } & \multirow[b]{3}{*}{$P$} \\
\hline & \multicolumn{2}{|c|}{ Breast-feeding $^{*}$} & \multicolumn{2}{|c|}{ Formula feeding $\dagger$} & \\
\hline & $n$ & $\%$ & $n$ & $\%$ & \\
\hline \multicolumn{6}{|l|}{ UIC ( $\mu \mathrm{g} / \mathrm{l})$} \\
\hline \multicolumn{6}{|l|}{ Infants } \\
\hline Median & \multirow{2}{*}{\multicolumn{2}{|c|}{$\begin{array}{c}183 \\
76-285\end{array}$}} & \multirow{2}{*}{\multicolumn{2}{|c|}{$\begin{array}{c}140 \\
68-290\end{array}$}} & 0.810 \\
\hline IQR & & & & & \\
\hline$<100$ & 19 & 35 & 16 & 39 & 0.701 \\
\hline$\geq 100$ & 35 & 65 & 25 & 61 & \\
\hline \multicolumn{6}{|l|}{ Mothers } \\
\hline Median & \multirow{2}{*}{\multicolumn{2}{|c|}{$\begin{array}{c}78 \\
42-145\end{array}$}} & \multirow{2}{*}{\multicolumn{2}{|c|}{$\begin{array}{c}87 \\
44-159\end{array}$}} & 0.421 \\
\hline IQR & & & & & \\
\hline$<100$ & 47 & 68 & 30 & 59 & 0.294 \\
\hline$\geq 100$ & 22 & 32 & 21 & 41 & \\
\hline \multicolumn{6}{|l|}{$\mathrm{BMIC}(\mu \mathrm{g} / \mathrm{l})$} \\
\hline Median & \multirow{2}{*}{\multicolumn{2}{|c|}{$\begin{array}{c}100 \\
83-147\end{array}$}} & \multirow{2}{*}{\multicolumn{2}{|c|}{$\begin{array}{c}122 \ddagger \\
77-172\end{array}$}} & 0.254 \\
\hline IQR & & & & & \\
\hline$<150$ & 55 & 79 & $17 \ddagger$ & 59 & 0.069 \\
\hline$\geq 150$ & 15 & 21 & $12 \ddagger$ & 41 & \\
\hline
\end{tabular}

compared with 59 and $35 \%$, respectively, of formula feeding mothers. The median BMIC values were $100 \mu \mathrm{g} / 1$ (IQR 83-147) among breast-feeding mothers, compared with $122 \mu \mathrm{g} / \mathrm{l}$ (IQR 77-172) among formula feeding mothers $(P=0 \cdot 254)$. The median iodine concentrations in the salt samples were $26 \mathrm{ppm}$ (IQR 20-32) in the breast-feeding group and $25 \mathrm{ppm}$ (IQR 20-29) in the formula feeding group $(P=0 \cdot 155)$. The iodine content of the selected formula brands ( $n$ 9) were $5-18 \mu \mathrm{g} / 100 \mathrm{ml}$, which was often higher than the labelled amount (Table 3), with differences that ranged from -5 to $+4 \mu \mathrm{g} /$ $100 \mathrm{ml}$.

The maternal UIC values were significantly correlated with the BMIC values $(r 0 \cdot 36, P<0.001)$ and the infants' UIC values ( $r$ 0.21, $P=0.04$ ). In addition, the BMIC values were significantly correlated with the infants' UIC values $(r 0.35$, $P=0 \cdot 001$ ) (Fig. 1). However, the salt samples' iodine contents were not significantly correlated with the BMIC or UIC values. Analysis of covariance revealed that BMIC significantly affected the infants' iodine status $(P=0.002)$. However, after adjustment for BMIC, feeding type (exclusive breastfeeding $v$. partial formula feeding) did not affect the mothers' or infants' UIC values.

\section{Discussion}

To the best of our knowledge, the present study is one of the first to compare UIC values between breast-fed and formula-fed infants, as well as their mothers, in Iran, where iodised salt is the main dietary iodine source for all age groups, including lactating mothers and their infants. The present study revealed no significant differences in the mothers' and infants' UIC values according to feeding type. Furthermore, although BMIC was significantly correlated with the infants' iodine status, the
Table 3. Comparison of labelled and measured iodine content in different brands of infant formula

\begin{tabular}{lcccc}
\hline $\begin{array}{l}\text { Adapted } \\
\text { formula } \\
\text { brands }\end{array}$ & $\begin{array}{c}\text { Labelled } \\
\text { iodine } \\
(\mu \mathrm{g} / 100 \mathrm{~g})\end{array}$ & $\begin{array}{c}\text { Labelled } \\
\text { iodine } \\
(\mu \mathrm{g} / 100 \mathrm{ml})\end{array}$ & $\begin{array}{c}\text { Measured } \\
(\mu \mathrm{g} / 100 \mathrm{ml})^{\star}\end{array}$ & $\begin{array}{r}\text { Differences } \\
(\mu \mathrm{g} / 100 \mathrm{ml}) \dagger\end{array}$ \\
\hline Aptamil-1 & 75 & 10 & 14 & 4 \\
Biomil-1 & 78 & - & 9 & - \\
Biomil Plus-1 & 74 & 14 & 18 & 4 \\
Nan-1 & 95 & 12 & 15 & 3 \\
Bebelac-1 & 90 & 12 & 16 & 4 \\
Guigoz-1 & 95 & 12 & 16 & 4 \\
Tro Vital-1 & 130 & - & 12 & - \\
Supramil-1 & 70 & 9 & 13 & -5 \\
Isomil-1 & 76 & 10 & 5 & -5 \\
\hline
\end{tabular}

* Measured using the Sandell-Kolthoff (acid-digestion) reaction.

† Differences of measured iodine concentration compared with labelled iodine concentration based on $\mu \mathrm{g} / 100 \mathrm{ml}$ formula.

feeding type (exclusive breast-feeding $v$. partial formula feeding) did not affect the infants' and mothers' UIC values in the analyses that were adjusted for BMIC.

According to the international criteria, the median UIC in a representative sample of schoolchildren provides a reliable assessment of a population's iodine status. However, there is significant evidence that pregnant and/or lactating women can have a suboptimal iodine status in areas with iodine sufficiency. For example, iodine sufficiency among school-aged children was not accompanied by adequate UIC values among pregnant and/or lactating women in Switzerland ${ }^{(20)}$, Iran ${ }^{(24)}$, Australia ${ }^{(25)}$ and New Zealand ${ }^{(26)}$. However, data from different countries have indicated that, in areas with iodine sufficiency or even mild ID, infants' needs for iodine and thyroid hormones are sufficiently fulfilled using breast milk, because of a compensatory mechanism in the mammary glands that leads to 

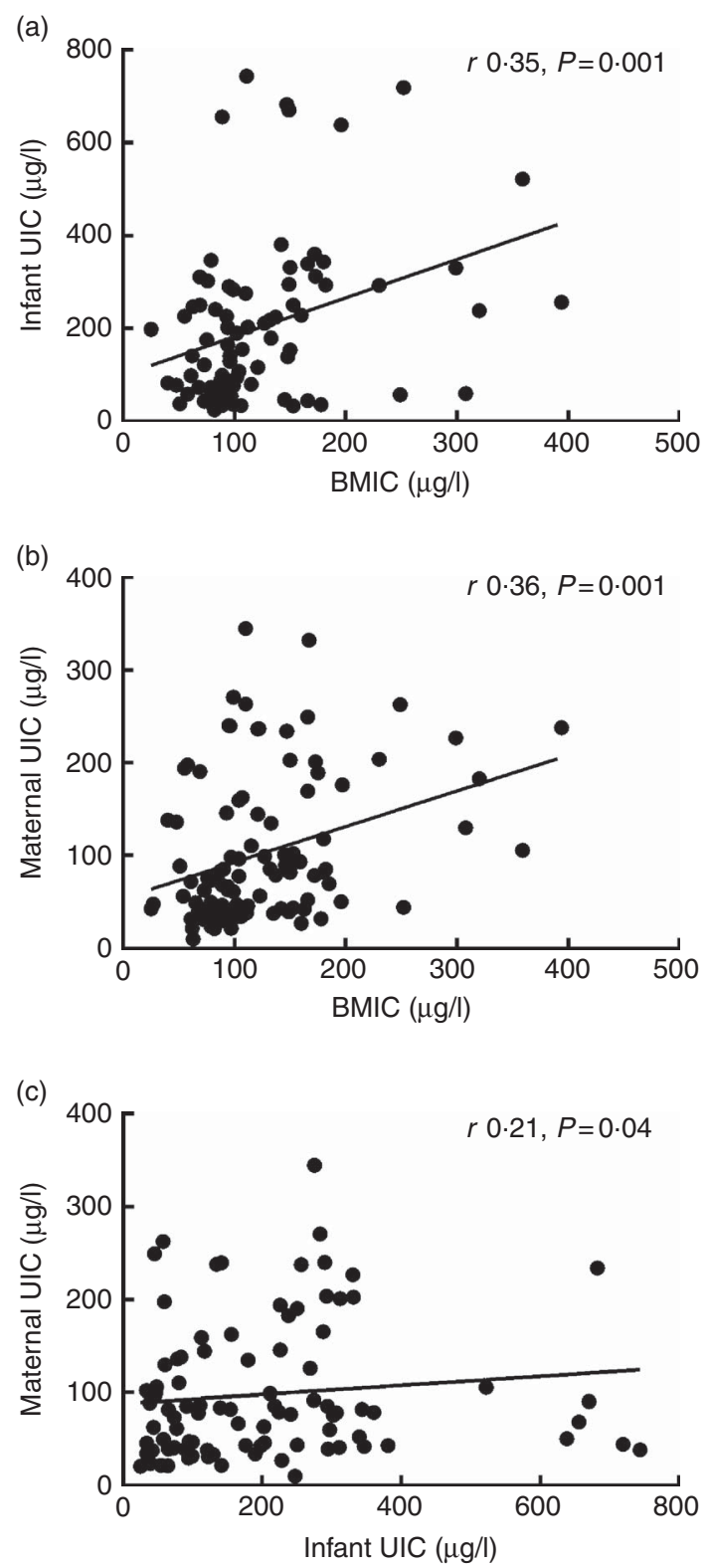

Fig. 1. Correlations between infants' urinary iodine concentration (UIC) and breast milk iodine concentration (BMIC) (a), between maternal UIC and BMIC (b), and between maternal and infants' UIC (c).

up-regulation of the sodium-iodide symporter and sufficient transfer of iodine from mother to infant ${ }^{(20,27-30)}$. Present data confirm that iodine adequacy among infants may be accompanied by suboptimal iodine status among lactating mothers, which was observed more in the exclusive breast-feeding group than the formula feeding group. Similarly, a significant proportion of exclusively breast-fed infants and their mothers have ID in India, although the infants' iodine status is relatively protected $^{(31)}$. Similar patterns were observed among lactating mothers and their infants in China $(122 v .183 \mu \mathrm{g} / \mathrm{l})$, Ireland $(76 v .100 \mu \mathrm{g} / \mathrm{l})$ and Turkey (40 v. $85 \mu \mathrm{g} / \mathrm{l})$, which indicates that lactating mothers have lower UIC values than their infants ${ }^{(13-15)}$.

Given the broad ranges of BMIC in countries with iodine sufficiency $^{(12,23,32,33)}$, there is no consensus regarding the required iodine levels in breast milk that are needed to adequately fulfil infants' iodine requirements ${ }^{(7,34-36)}$. For example, reported BMIC values are $46-155 \mu \mathrm{g} / 1$ in the $\mathrm{USA}^{(29,37,38)}$ and $58-170 \mu \mathrm{g} / \mathrm{l}$ in $\operatorname{Iran}^{(17,39,40)}$. These differences may be related to several factors that can affect BMIC values, including maternal iodine status ${ }^{(23,32,36)}$, recent maternal iodine intake ${ }^{(41)}$, duration of lactation $^{(42)}$ and maternal fluid intake ${ }^{(27)}$, of which maternal iodine status plays the most crucial role. In addition, despite the mechanism that enhances iodine excretion in the mother's mammary glands, different studies have indicated that mothers with suboptimal iodine status have lower BMIC values, compared with mothers with adequate iodine status. For example, lactating mothers with ID have inadequate BMIC values in Australia $^{(43)}$, Turkey $^{(44)}$ and Portugal ${ }^{(45)}$, whereas lactating mothers in $\operatorname{Iran}^{(17,46)}$ and the $\mathrm{USA}^{(29)}$ (areas with iodine sufficiency) have BMIC values that are within the optimal range. Similarly, a recent study by Dold et al. ${ }^{(47)}$ revealed that lactating mothers with an adequate iodine status had greater fractional iodine excretion in their breast milk, compared with their urine, although a relatively constant proportion (approximately 33\%) of total iodine was excreted in breast milk from mothers with ID. There is some evidence that BMIC can be used to monitor the iodine status of breast-fed infants ${ }^{(48)}$, although this relationship remains speculative, given the limited number of relevant studies. The present finding is compatible with our previous reports that revealed a significant positive correlation between BMIC and infants' UIC values ${ }^{(17,39,46)}$. Furthermore, in the USA and China, iodine sufficiency among infants was also accompanied by adequate iodine levels in breast milk ${ }^{(15,19)}$.

Only a few studies have compared the iodine contents of breast milk and infant formula, and related those findings to infants' iodine status according to feeding type in areas with iodine sufficiency. A recent report from Switzerland indicates that partially breast-fed and formula-fed infants had higher UIC values than infants who were exclusively breast-fed (109 $v$. $73 \mu \mathrm{g} / \mathrm{l})$, which was attributed to the higher iodine content of infant formula $(45-148 \mu \mathrm{g} / \mathrm{l})$, compared with breast milk $(40-80 \mu \mathrm{g} / \mathrm{l})^{(20)}$. The present study revealed that the iodine content of infant formula was $50-184 \mu \mathrm{g} / \mathrm{l}$, whereas the median BMIC values were $100 \mu \mathrm{g} / 1(40-320 \mu \mathrm{g} / \mathrm{l})$ in the exclusive breastfeeding group and $122 \mu \mathrm{g} / \mathrm{l}(25-394 \mu \mathrm{g} / \mathrm{l})$ in the group that received breast milk and formula. In addition, although the difference was not significant, exclusively breast-fed infants had higher UIC values, compared with infants who received formula. Similarly, an American study ${ }^{(29)}$ revealed no significant difference between the median iodine concentrations of breast milk and infant formula ( $155 \mu \mathrm{g} / \mathrm{l}, n 57 v .145 \mu \mathrm{g} / \mathrm{l}, n$ 17). It also found similar iodine statuses among infants who were exclusively breast-fed (203 $\mu \mathrm{g} / \mathrm{l}, n$ 39), formula-fed (182.5 $\mu \mathrm{g} / \mathrm{l}, n 44)$ or received breast milk and formula $(198 \mu \mathrm{g} / 1, n 10)^{(19)}$.

The main strength of the present study is the simultaneous assessment of iodine status among breast-fed and formula-fed infants, as well as their mothers, in an area with a successful salt iodisation programme. However, the present study only evaluated individuals from randomly selected regions of Tehran, and the data may not be representative of the entire city. Therefore, caution should be taken in generalising these findings to other areas and populations. In addition, the use of a 
single urine sample is a poor indicator of long-term iodine status $^{(49)}$, as intra-individual variability could be introduced through maternal dietary intake of iodine (i.e. iodised salt in Iran), maternal hydration and the iodine content and amount of the formula and/or breast milk that the infant receives. Furthermore, programmes promoting the importance of breastfeeding, as well as low family incomes and relatively high formula prices, resulted in a limited number of mothers who exclusively fed their children formula ( $n$ 15). Thus, categorisation of the mothers into groups that exclusively breast-fed, partially formula fed, and exclusively formula fed could lead to inadequately powered statistical analyses.

In conclusion, the present study revealed that in Tehran (an area with iodine sufficiency based on the median UIC from the WHO), there were no differences in infants' or mothers' urinary iodine levels according to the feeding type and the iodine statuses of mothers and their infants were not affected by the type of feeding. Thus, both breast milk with adequate iodine levels and infant formula that is supplemented with iodine can fulfil infants' iodine requirements during the first 6 months of life.

\section{Acknowledgements}

We would like to thank the mothers and their infants who participated in the study.

This study was supported by financial grant from the Research Institute of Endocrine Sciences, Shahid Beheshti University of Medical Sciences

P. N. contributed to the design, data analysis and writing of the manuscript; H. D. contributed to the design, writing, reading and final approval of the manuscript; Y. M. contributed to the statistical analysis and writing of the manuscript; M. H. contributed to the design of the study and writing of the manuscript; P. M. and F. A. contributed to the design of the study, writing, reading and final approval of the manuscript.

The authors declare that there are no conflicts of interest.

\section{References}

1. Zimmermann MB (2011) The role of iodine in human growth and development. Semin Cell Dev Biol 22, 645-652.

2. Zimmermann MB (2016) The importance of adequate iodine during pregnancy and infancy. World Rev Nutr Diet $\mathbf{1 1 5}$ 118-124.

3. Melse-Boonstra A \& Jaiswal N (2010) Iodine deficiency in pregnancy, infancy and childhood and its consequences for brain development. Best Pract Res Clin Endocrinol Metab 24, 29-38.

4. Pearce EN, Lazarus JH, Moreno-Reyes R, et al. (2016) Consequences of iodine deficiency and excess in pregnant women: an overview of current knowns and unknowns. Am J Clin Nutr 104, Suppl. 3, 918S-923S.

5. Bath SC, Steer CD, Golding J, et al. (2013) Effect of inadequate iodine status in UK pregnant women on cognitive outcomes in their children: results from the Avon Longitudinal Study of Parents and Children (ALSPAC). Lancet 382, 331-337.

6. Zimmermann MB (2012) The effects of iodine deficiency in pregnancy and infancy. Paediatr Perinat Epidemiol 26, Suppl. 1, 108-117.
7. Zimmermann MB, Jooste PL \& Pandav CS (2008) Iodinedeficiency disorders. Lancet 372, 1251-1262.

8. Berbel P, Mestre JL, Santamaria A, et al. (2009) Delayed neurobehavioral development in children born to pregnant women with mild hypothyroxinemia during the first month of gestation: the importance of early iodine supplementation. Thyroid 19, 511-519.

9. Hynes KL, Otahal P, Hay I, et al. (2013) Mild iodine deficiency during pregnancy is associated with reduced educational outcomes in the offspring: 9-year follow-up of the gestational iodine cohort. J Clin Endocrinol Metab 98, 1954-1962.

10. Abel MH, Caspersen IH, Meltzer HM, et al. (2017) Suboptimal maternal iodine intake is associated with impaired child neurodevelopment at 3 years of age in the Norwegian mother and child cohort study. J Nutr 147, 1314-1324.

11. Pearce EN, Andersson M \& Zimmermann MB (2013) Global iodine nutrition: where do we stand in 2013? Thyroid 23, 523-528.

12. Azizi F \& Smyth P (2009) Breastfeeding and maternal and infant iodine nutrition. Clin Endocrinol (Oxf) 70, 803-809.

13. Simsek E, Karabay M \& Kocabay K (2005) Neonatal screening for congenital hypothyroidism in West Black Sea area, Turkey. Int J Clin Pract 59, 336-341.

14. Smyth PP, Hetherton AM, Smith DF, et al. (1997) Maternal iodine status and thyroid volume during pregnancy: correlation with neonatal iodine intake. J Clin Endocrinol Metab 82, 2840-2843.

15. Zhang JH, Xu H, Zhan L, et al. (2003) [Effects of different feeding methods on the iodine status of the infants during the weaning period]. Zhonghua Er Ke Za Zhi 41, 483-485.

16. Nazeri P, Mirmiran P, Hedayati M, et al. (2016) Can postpartum maternal urinary iodine be used to estimate iodine nutrition status of newborns? Br J Nutr 115, 1226-1231.

17. Ordookhani A, Pearce EN, Hedayati M, et al. (2007) Assessment of thyroid function and urinary and breast milk iodine concentrations in healthy newborns and their mothers in Tehran. Clin Endocrinol (Oxf) 67, 175-179.

18. Smyth PP, Smith DF, Sheehan S, et al. (2007) Short-term changes in maternal and neonatal urinary iodine excretion. Thyroid 17, 219-222.

19. Gordon JH, Leung AM, Hale AR, et al. (2014) No difference in urinary iodine concentrations between Boston-area breastfed and formula-fed infants. Thyroid 24, 1309-1313.

20. Andersson M, Aeberli I, Wust N, et al. (2010) The Swiss iodized salt program provides adequate iodine for school children and pregnant women, but weaning infants not receiving iodine-containing complementary foods as well as their mothers are iodine deficient. J Clin Endocrinol Metab 95, 5217-5224

21. Hedayati M, Khazan M, Yaghmaee P, et al. (2011) Rapid microwave digestion and microplate reading format method for urinary iodine determination. Clin Chem Lab Med 49, 281-284.

22. World Health Organization (2007) Assessment of iodine deficiency disorders and monitoring their elimination: a guide for programme managers. http://apps.who.int/iris/bitstream/ 10665/43781/1/9789241595827_eng.pdf (accessed August 2017).

23. Dorea JG (2002) Iodine nutrition and breast feeding. J Trace Elem Med Biol 16, 207-220.

24. Nazeri P, Zarghani NH, Mirmiran P, et al. (2016) Iodine status in pregnant women, lactating mothers, and newborns in an area with more than two decades of successful iodine nutrition. Biol Trace Elem Res 172, 79-85. 
25. Axford S, Charlton K, Yeatman H, et al. (2011) Improved iodine status in breastfeeding women following mandatory fortification. Aust N Z J Public Health 35, 579-580.

26. Brough L, Jin Y, Shukri NH, et al. (2013) Iodine intake and status during pregnancy and lactation before and after government initiatives to improve iodine status, in Palmerston North, New Zealand: a pilot study. Matern Child Nutr 2013, 12055.

27. Andersen SL, Moller M \& Laurberg P (2014) Iodine concentrations in milk and in urine during breastfeeding are differently affected by maternal fluid intake. Thyroid $\mathbf{2 4}$, 764-772.

28. Liu L, Wang D, Liu P, et al. (2015) The relationship between iodine nutrition and thyroid disease in lactating women with different iodine intakes. Br J Nutr 114, 1487-1495.

29. Pearce EN, Leung AM, Blount BC, et al. (2007) Breast milk iodine and perchlorate concentrations in lactating Bostonarea women. J Clin Endocrinol Metab 92, 1673-1677.

30. Sukkhojaiwaratkul D, Mahachoklertwattana P, Poomthavorn P, et al. (2014) Effects of maternal iodine supplementation during pregnancy and lactation on iodine status and neonatal thyroid-stimulating hormone. J Perinatol 34, 594-598.

31. Gupta R, Seth A, Pandav CS, et al. (2006) Iodine nutrition status of exclusively breast-fed infants and their mothers in New Delhi, India. J Pediatr Endocrinol Metab 19, 1429-1435.

32. Semba RD \& Delange F (2001) Iodine in human milk: perspectives for infant health. Nutr Rev 59, 269-278.

33. Henjum S, Lilleengen AM, Aakre I, et al. (2017) Suboptimal iodine concentration in breastmilk and inadequate iodine intake among lactating women in Norway. Nutrients $\mathbf{9}, 643$.

34. Swanson CA \& Pearce EN (2013) Iodine insufficiency: a global health problem? Adv Nutr 4, 533-535.

35. Swanson CA, Zimmermann MB, Skeaff S, et al. (2012) Summary of an NIH workshop to identify research needs to improve the monitoring of iodine status in the United States and to inform the DRI. J Nutr 142, 1175S-1185S

36. Zimmermann MB (2009) Iodine deficiency. Endocr Rev 30, $376-408$

37. Leung AM, Braverman LE, He X, et al. (2012) Environmental perchlorate and thiocyanate exposures and infant serum thyroid function. Thyroid 22, 938-943.

38. Hannan MA, Faraji B, Tanguma J, et al. (2009) Maternal milk concentration of zinc, iron, selenium, and iodine and its relationship to dietary intakes. Biol Trace Elem Res 127, 6-15.
39. Bazrafshan HR, Mohammadian S, Ordookhani A, et al. (2005) An assessment of urinary and breast milk iodine concentrations in lactating mothers from Gorgan, Iran, 2003. Thyroid 15, $1165-1168$

40. Mobasseri M, Roshanravan N, Mesri Alamdari N, et al. (2014) Urinary and milk iodine status in neonates and their mothers during congenital hypothyroidism screening program in Eastern Azerbaijan: a pilot study. Iran $J$ Public Health 43, 1380-1384.

41. Leung AM, Braverman LE, He X, et al. (2012) Breastmilk iodine concentrations following acute dietary iodine intake. Thyroid 22, 1176-1180.

42. Mulrine HM, Skeaff SA, Ferguson EL, et al. (2010) Breast-milk iodine concentration declines over the first 6 mo postpartum in iodine-deficient women. Am J Clin Nutr $\mathbf{9 2}$, 849-856.

43. Chan SS, Hams G, Wiley V, et al. (2003) Postpartum maternal iodine status and the relationship to neonatal thyroid function. Thyroid 13, 873-876.

44. Kurtoglu S, Akcakus M, Kocaoglu C, et al. (2004) Iodine status remains critical in mother and infant in Central Anatolia (Kayseri) of Turkey. Eur J Nutr 43, 297-303.

45. Costeira MJ, Oliveira P, Ares S, et al. (2009) Iodine status of pregnant women and their progeny in the Minho Region of Portugal. Thyroid 19, 157-163.

46. Hashemipour M, Nasri P, Hovsepian S, et al. (2010) Urine and milk iodine concentrations in healthy and congenitally hypothyroid neonates and their mothers. Endokrynol Pol 61, 371-376.

47. Dold S, Zimmermann MB, Aboussad A, et al. (2017) Breast milk iodine concentration is a more accurate biomarker of iodine status than urinary iodine concentration in exclusively breastfeeding women. J Nutr 147, 528-537.

48. Dold S, Baumgartner J, Zeder C, et al. (2016) Optimization of a new mass spectrometry method for measurement of breast milk iodine concentrations and an assessment of the effect of analytic method and timing of within-feed sample collection on breast milk iodine concentrations. Thyroid 26, 287-295.

49. Konig F, Andersson M, Hotz K, et al. (2011) Ten repeat collections for urinary iodine from spot samples or 24-hour samples are needed to reliably estimate individual iodine status in women. J Nutr 141, 2049-2054. 